\title{
Atmospheric ozone above Troll station, Antarctica observed by a ground based microwave radiometer
}

\author{
M. Daae ${ }^{1,2}$, C. Straub ${ }^{1,3}$, P. J. Espy ${ }^{1,2}$, and D. A. Newnham ${ }^{4}$ \\ ${ }^{1}$ Norwegian University of Science and Technology, Department of Physics, Trondheim, Norway \\ ${ }^{2}$ Birkeland Centre for Space Science, Bergen, Norway \\ ${ }^{3}$ Institute of Applied Physics, University of Bern, Bern, Switzerland \\ ${ }^{4}$ British Antarctic Survey, Cambridge, UK \\ Correspondence to: M. Daae (marianne.daae@ntnu.no)
}

Received: 6 August 2013 - Published in Earth Syst. Sci. Data Discuss.: 5 September 2013

Revised: 11 February 2014 - Accepted: 16 February 2014 - Published: 21 March 2014

\begin{abstract}
This paper describes the stratospheric and mesospheric ozone profiles retrieved from spectral measurements of the $249.96 \mathrm{GHz} \mathrm{O}_{3}$ line, using the British Antarctic Survey's ground-based Microwave Radiometer at Troll (BAS-MRT), Antarctica $\left(72^{\circ} 01^{\prime} \mathrm{S}, 02^{\circ} 32^{\prime} \mathrm{E}, 62^{\circ}\right.$ Mlat). The instrument operated at Troll from February 2008 through January 2010, and hourly averaged spectra were used to retrieve approximately 20 ozone profiles per day. The ozone profiles cover the pressure range from $3 \mathrm{hPa}$ to $0.02 \mathrm{hPa}$ (approximately 38 to $72 \mathrm{~km}$ ) which includes the topside of the stratospheric ozone layer and the peak of the tertiary maximum. Comparing the retrieved ozone volume mixing ratio (vmr) values to Aura/MLS and SD-WACCM shows no significant bias to within the instrumental uncertainties. The long-term variations ( $>20$ days) between MLS and SD-WACCM agree well with BAS-MRT at all altitudes with significant correlation coefficients of at least 0.9 (0.7 with SD-WACCM) in the upper stratosphere and middle mesosphere. A weaker correlation is found for the long-term variations in summer when most of the vmr values are below the random noise level of Aura/MLS. The correlation of short-term variations ( $<20$ days) between MLS and BAS-MRT agree well at all altitudes with significant correlation coefficients of at least 0.7 in the upper stratosphere and middle mesosphere. The ozone profiles retrieved at Troll, Antarctica extend the sparse data coverage of middle atmospheric ozone above Antarctica, where, due to the dynamic nature of the ozone concentrations, systematic observations with a high temporal resolution are desirable. The $\mathrm{O}_{3}$ profiles presented here are stored at the UK's Polar Data Centre (http://doi.org/nc3) and are available for public scientific use.
\end{abstract}

\section{Introduction}

Ozone concentrations in the middle atmosphere are governed by UV photolysis of $\mathrm{O}_{2}, \mathrm{O}_{3}$ and $\mathrm{H}_{2} \mathrm{O}$, and catalytic cycles involving odd hydrogen $\left(\mathrm{HO}_{\mathrm{x}}=\mathrm{H}, \mathrm{OH}, \mathrm{HO}_{2}\right)$. The stratospheric ozone maximum near $30 \mathrm{~km}$ is associated with near- and mid-ultraviolet (UV) photo-dissociation of $\mathrm{O}_{2}$ followed by recombination. The secondary maximum near the mesopause (Hays and Roble, 1973) results from the downward transport and recombination of $\mathrm{O}$ associated with FarUV (FUV) dissociation of $\mathrm{O}_{2}$ in the lower thermosphere. Between these two maxima in the summer, the availability of $\mathrm{HO}_{\mathrm{x}}$ results in a deep minimum in the mesospheric ozone abundance. However, during winter near the polar-night terminator, a tertiary maximum occurs near $70 \mathrm{~km}$ where $\mathrm{H}_{2} \mathrm{O}$ is no longer efficiently dissociated into odd hydrogen due to high optical depths in the FUV (Marsh et al., 2001). This ozone peak in the middle mesosphere can be observed from early fall until late spring, extending approximately $30^{\circ}$ in latitude from the equatorward edge of the polar-night terminator (Hartogh et al., 2004).

Ozone in the middle mesosphere undergoes a strong diurnal cycle as the odd oxygen is cycled between $\mathrm{O}$ during the day and $\mathrm{O}_{3}$ at night. The resulting ozone mixing ratio can go from close to 0 ppmv during the day and reach 3-4 ppmv in 
the course of a few hours during twilight. Planetary waves, tides and gravity waves also cause variations in the tertiary maximum as indicated by (Hartogh et al., 2004). In addition, space weather effects can cause significant loss of $\mathrm{O}_{3}$ throughout the middle atmosphere (e.g. Solomon et al., 1982; Jackman et al., 2009; Daae et al., 2012). This can occur by direct precipitation of charged particles into the mesosphere that increase $\mathrm{NO}_{\mathrm{x}}$ levels by up to 2.6 gigamoles per year (e.g. Turunen et al., 2009; Randall et al., 2006) and enhance $\mathrm{HO}_{\mathrm{x}}$ levels by $100 \%$ (e.g. Verronen et al., 2011), locally depressing $\mathrm{O}_{3}$ levels due to catalytic reactions.

Ground-based observations of $\mathrm{O}_{3}$ in the mesosphere using microwave radiometry have been primarily located in the Northern Hemisphere (e.g. Muscari et al., 2012; Palm et al., 2010). Hartogh et al. (2004), using the $142 \mathrm{GHz} \mathrm{O}$ line in northern Norway $\left(69.29^{\circ} \mathrm{N}, 10.13^{\circ} \mathrm{E}\right)$, observed large ozone variations within the 1995-1996 winter season, which they attributed to modulations of the dynamics controlling the availability of $\mathrm{H}_{2} \mathrm{O}$. Sonnemann et al. (2007) used a microwave technique at Lindau, Germany $\left(51.66^{\circ} \mathrm{N}, 10.13^{\circ} \mathrm{E}\right)$ to analyze the night-to-day ratio of ozone in the mesosphere. They found that while night-time ozone levels are enhanced due to a west-wind regime, the daytime ozone is less influenced by the zonal wind.

Ground-based radiometer observations of ozone in the Southern Hemisphere are sparse with systematic observations only at mid-latitudes in New Zealand and South America (McDermid et al., 1998; Orte et al., 2011), and from Antarctica during the years 1993, 1995 and 1999 (Nemuc and De Zafra, 2007). Here we describe nearly two years of continuous ground-based radiometer measurements of ozone above Troll, Antarctica $\left(72^{\circ} 01^{\prime} \mathrm{S}, 02^{\circ} 32^{\prime} \mathrm{E}, 1270 \mathrm{~m}\right.$ above sea level) covering the upper stratosphere and lower mesosphere. The instrument, as well as its location within the polar vortex and at high geomagnetic latitude $\left(62^{\circ}\right.$ Mlat, $L=$ 4.76), allows both short- and long-term chemical and dynamical variations as well as the impact on the $\mathrm{O}_{3}$ from charged particle precipitation to be studied (Newnham et al., 2011; Daae et al., 2012; Demissie et al., 2013).

\section{Measurement}

The British Antarctic Survey's Microwave Radiometer at Troll (BAS-MRT) measures spectral regions around the rotational transitions of nitric oxide (NO) at $250.796 \mathrm{GHz}$ (Newnham et al., 2011), carbon monoxide (CO) at $230.538 \mathrm{GHz}$ (Straub et al., 2013) and ozone $\left(\mathrm{O}_{3}\right)$ at $249.96 \mathrm{GHz}$. The $\mathrm{O}_{3}$ observations, and the retrieved altitude profiles, are presented here.

\subsection{Instrument and calibration}

BAS-MRT observes at an azimuth angle of $288^{\circ}$ and a zenith angle of $60^{\circ}$, which is in the direction toward the SANAE research station as seen in Fig. 1. The instrument field of view

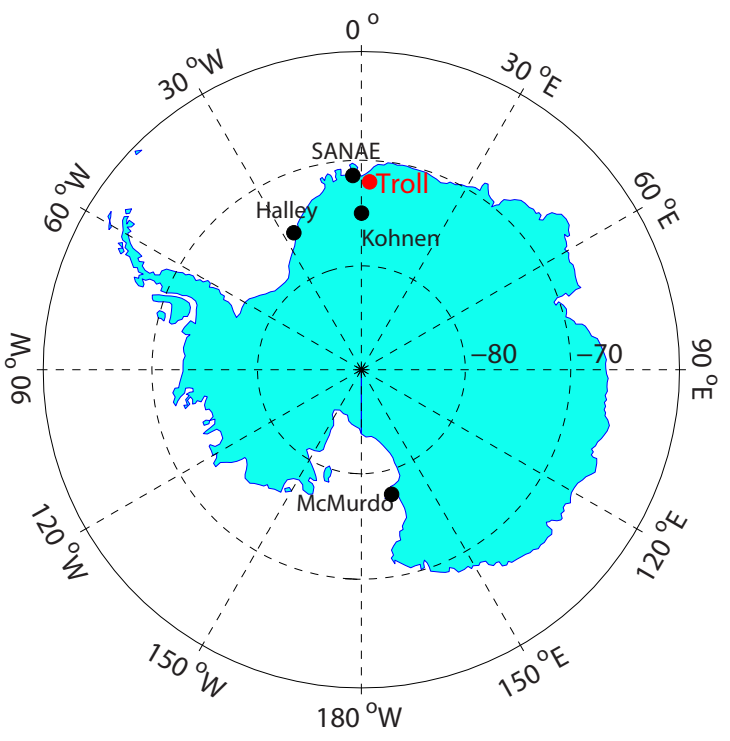

Figure 1. Location of BAS-MRT at the Troll research facility in Antarctica $\left(72^{\circ} 01^{\prime} \mathrm{S}, 02^{\circ} 32^{\prime} \mathrm{E}\right)$. The instrument's view direction is $288^{\circ}$ azimuth (toward SANAE), with a zenith angle of $60^{\circ}$.

intercepts altitudes of 40,60 and $80 \mathrm{~km}$ at geographical locations $\left(71.81^{\circ} \mathrm{S}, 0.58^{\circ} \mathrm{E}\right),\left(71.71^{\circ} \mathrm{S}, 0.37^{\circ} \mathrm{W}\right)$ and $\left(71.62^{\circ} \mathrm{S}\right.$, $\left.1.33^{\circ} \mathrm{W}\right)$, respectively.

The instrument consists of a cryogenically cooled radiometric front-end coupled to a spectrometer backend. In the front-end heterodyne receiver, the incoming radiation is combined with an independent local oscillator signal at $255.6 \mathrm{GHz}$ by a Superconductor-Insulator-Superconductor mixer cooled to $4 \mathrm{~K}$. The intermediate frequency (IF) signal in the 4 to $6 \mathrm{GHz}$ range is then amplified. For $\mathrm{O}_{3}$ measurements the signal is further down-converted to $2.1 \mathrm{GHz}$ and analyzed using a Chirp Transform Spectrometer (CTS) (Hartogh and Hartmann, 1990; Villanueva and Hartogh, 2004; Villanueva et al., 2006) with a $28 \mathrm{kHz}$ resolution and $220 \mathrm{MHz}$ bandwidth.

A three-way chopper system selects the microwave emission either from the atmosphere, a $60 \mathrm{~K}$ cold calibration load or a room temperature hot calibration load and directs it into the main receiver. The atmospheric signal is then calibrated using the switching technique of Dicke and Beringer (1946) as described by Parrish (1994, and references therein). The signal from each target is integrated by the spectrometer for $8 \mathrm{~s}$, resulting in a calibrated $\mathrm{O}_{3}$ spectrum every $17.5 \mathrm{~s}$. Further details about the radiometer and its measurements can be found in Espy et al. (2006) and Straub et al. (2013).

The $\mathrm{O}_{3}$ signal is modified by absorption and emission due to other atmospheric species, predominantly in the troposphere by water vapor. This is accounted for by calculating a tropospheric correction factor for each spectrum, as described in Forkman et al. (2012). 


\subsection{Dataset}

BAS-MRT made observations corresponding to the data presented in this paper from February 2008 through January 2010. On average, the $\mathrm{O}_{3}$ line was observed for approximately $20 \mathrm{~h}$ each day, as around 12:00 UTC (GMT) the frequency of the local oscillator was manually changed and the instrument observed CO for two hours (Straub et al., 2013). To increase the Signal to Noise $(S / N), \mathrm{O}_{3}$ spectra are integrated for one hour (typically 203 spectra). The 1- $\sigma$ noise level on the integrated spectra, measured far from the line centre, is typically less than $0.2 \mathrm{~K}$. However, occasional contaminated spectra will raise the noise level far beyond this and result in an unrealistic profile inversion. To prevent this, we did not consider integrated spectra with a noise level greater than $0.71 \mathrm{~K}$, that is $2-\sigma$ above the average noise level. Figure 2 shows example $\mathrm{O}_{3}$-spectra for summer noon and winter midnight, and indicates the spectral region used in the retrievals described below as well as the variable instrumental baseline.

\section{Retrieval of vertical profiles}

The spectra are inverted into altitude profiles using an iterative optimal estimation method (Rodgers, 2004) implemented in the Qpack (a part of atmlab v. 2.1.248) software package (Eriksson et al., 2005). The forward model, Atmospheric Radiative Transfer Simulator 2 (ARTS 2 v. 2.1.459), handles the radiative transfer through the atmosphere for different species and instrument configurations (Eriksson et al., 2011).

\subsection{Retrieval set-up}

As may be seen in Fig. 2, the spectra contain the pressureand Doppler- broadened $\mathrm{O}_{3}$ thermal emission line, and also a frequency dependent baseline that originates from standing waves in the front end of the radiometer. Thus, the retrieved quantities in the inversion are $\mathrm{O}_{3}$ volume mixing ratio (vmr), instrumental baseline and atmospheric temperature. The $\mathrm{O}_{3} \mathrm{vmr}$ is inverted from a $40 \mathrm{MHz}$ section of the spectrum centered on the $249.96 \mathrm{GHz} \mathrm{O} 3$ line. The baseline is approximated by a 1st order polynomial and the largest spectral component of the baseline, a 78.5 MHz period sinusoid. Testing of the baseline fit over this spectral range shows that these two components ensured optimal retrieval of the baseline without affecting the $\mathrm{O}_{3} \mathrm{vmr}$ values at lower altitudes. Spectroscopic parameters for the forward modeling of the $249.96 \mathrm{GHz} \mathrm{O}$ line are taken from the HITRAN 2008 Molecular Spectroscopic Database (Rothman et al., 2009).

The $\mathrm{O}_{3}$ vmr profiles are retrieved on a pressure grid corresponding to altitude levels from $15 \mathrm{~km}$ to $120 \mathrm{~km}$ with a $2 \mathrm{~km}$ spacing, where hydrostatic equilibrium is assumed for the altitude and pressure. The a priori for the atmospheric temperature and $\mathrm{O}_{3}$ profiles are taken from the Whole Atmo-

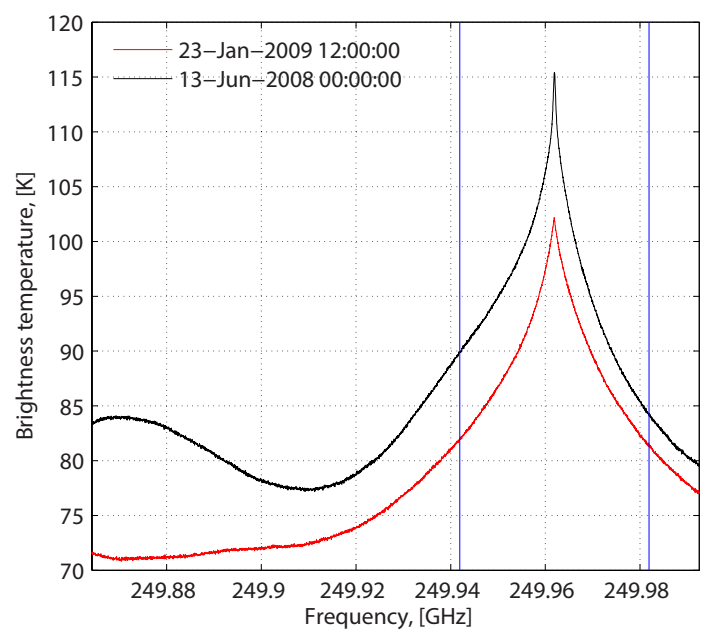

Figure 2. Noon summer (red) and midnight winter (black) calibrated atmospheric spectra. The blue vertical lines indicate the frequency range of the spectra used in the $\mathrm{O}_{3}$ retrieval.

sphere Community Climate Model with Specified Dynamics (SD-WACCM) version 3.5.48 (Garcia et al., 2007; Marsh, 2011; Lamarque et al., 2012). The a priori temperatures are the monthly means of a 20-year climatology, and the a priori of the $\mathrm{O}_{3}$ profiles are monthly means of a 4-year climatology (2004-2008). The a prioris are centered at the middle of each month, and intermediate values are linearly interpolated. To account for the diurnal cycle in the $\mathrm{O}_{3}$ we use day- and night- a priori depending on whether the solar elevation angle is above, or below $0^{\circ}$. The diagonal elements in the covariance of the $\mathrm{O}_{3}$ a priori are fixed at $0.09 \mathrm{ppmv}^{2}$, a value that is comparable to the mean of the variance in the $\mathrm{O}_{3}$ given by SD-WACCM. The shape of the covariance is set to linearly decrease toward the off-diagonal elements with a correlation length of 0.2 equivalent to a fifth of a pressure decade (about $3 \mathrm{~km}$ ).

\subsection{Results of the retrievals}

The retrieval of the $\mathrm{O}_{3}$ spectra resulted in 13648 profiles covering 675 days with an average of about 20 profiles per day. Figure 3 a shows examples from the results of the $\mathrm{O}_{3}$ retrievals and indicates the good quality of the spectral fits. The residuals, the data minus the fit, are shown in Fig. $3 \mathrm{~b}$ and show small remnants of baseline components that were not included in the fit. While the 1- $\sigma$ random noise component is less than $0.2 \mathrm{~K}$, the variation due to the unfitted baseline components (the long period oscillations in the residuals) give an effective noise about twice this. The figure also shows that while these components can vary from day to day, the total (random + residual baseline) variation remains on the order of $0.4 \mathrm{~K}$. The fitting program will adjust the $\mathrm{O}_{3}$ profile so that the calculated spectrum matches the observed spectrum to within the specified noise limit. By setting a noise limit of 

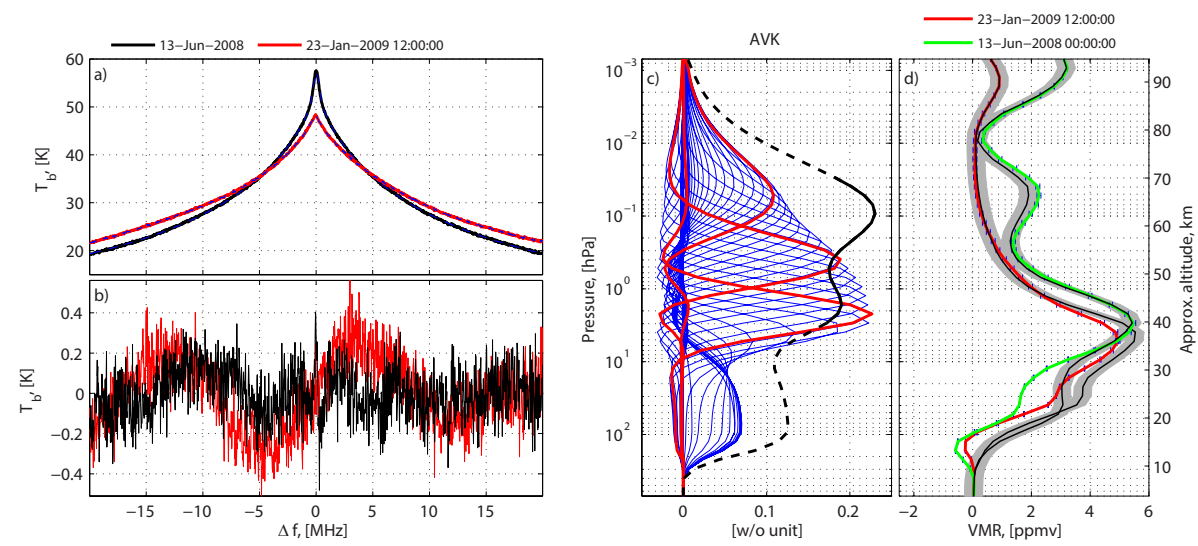

Figure 3. (a) Tropospheric- and baseline-corrected spectra for noon summer (red) and midnight winter (black), along with the fitted spectra (dashed blue). (b) Residuals between the corrected spectrum and the fitted spectrum for noon summer (red) and midnight winter (black). (c) The AVK from the retrieval, solid red lines are the AVK at $2.21 \mathrm{hPa}, 0.39 \mathrm{hPa}$ and $0.04 \mathrm{hPa}$ (approximately $41 \mathrm{~km}, 54 \mathrm{~km}$ and $71 \mathrm{~km}$ ). The black line is the measurement response from the AVK divided by 5, where the solid (dashed) part indicates the area of at least (less than) 0.8 measurement response. (d) Summer noon (red) and midnight winter profiles (green) with their barely visible random measurement error (blue error bars). The thin black solid line is the a priori with the grey shade showing the 1- $\sigma$ standard deviation of the a priori used in the retrieval.

$0.4 \mathrm{~K}$, rather than $0.2 \mathrm{~K}$, we ensure that the $\mathrm{O}_{3}$ profile is not modified in order to fit these small baseline components.

The Averaging Kernels (AVK) for each retrieved altitude are shown in Fig. 3c, describing the relationship between the true, a priori, and retrieved states of the atmosphere (Rodgers, 2004). AVK's indicate the range of altitudes over which the retrieved ozone concentration has smoothed the information in the data. Thus, the full-width at half-maximum (FWHM) of these kernels can be considered a measure of the vertical resolution of the retrieved profile. The FWHM of the AVK reveals an altitude resolution that varies from $10 \mathrm{~km}$ at $3 \mathrm{hPa}(39 \mathrm{~km})$ to $18 \mathrm{~km}$ at $0.7 \mathrm{hPa}(66 \mathrm{~km})$, indicating that that altitude resolution becomes coarser with increasing altitude as the ozone line width becomes dominated by the Doppler contribution rather than by pressure broadening.

At a given altitude, the sum of all the AVK's contributing to that altitude represents the degree to which the retrieved value there has been driven by the information from the measurement (Christensen and Eriksson, 2013, and references therein). The value of this sum is generally referred to as the measurement response (Baron et al., 2002; Rodgers, 2004) and is shown by the black line in Fig. 3c. The solid part of the curve shows where the measurement response is greater than 0.8 , indicating that between $3 \mathrm{hPa}$ and $0.02 \mathrm{hPa}$ (about 38 and $72 \mathrm{~km}$ ) the retrieved profile has a high degree of independence from the a priori (Christensen and Eriksson, 2013). Outside of these altitudes (i.e. below $38 \mathrm{~km}$ and above $72 \mathrm{~km}$ ) the measurement response weakens (shown by a dashed curve) and vmr values in these regions should be interpreted with caution as the information from the a priori becomes important.

Figure $3 \mathrm{~d}$ compares a summer noon and a winter midnight $\mathrm{O}_{3}$ profile. The summer noon profile shows the stratospheric ozone peak of $5 \mathrm{ppmv}$ at $35 \mathrm{~km}$, and the mesospheric minimum. The midnight winter profile shows the stratospheric ozone layer which has a similar magnitude to the summer time. The significant change from summer to winter occurs for the now apparent tertiary maximum with a peak value of $2.2 \mathrm{ppmv}$ at $69 \mathrm{~km}$. The secondary maximum is also seen in the summer and winter profiles, but the measurement response is $<0.8$, indicating that the data at these altitudes are dominated by the a priori.

Figure 4 shows the mesospheric (top panel) and the stratospheric (bottom panel) ozone vmr as observed by BAS-MRT over its two years of operation. The black solid line indicates the upper/lower limit of the 0.8 measurement response. This indicates that the topside of the stratospheric ozone layer is captured over the whole time period with a magnitude from 3 ppmv to $>6$ ppmv. The top panel in Fig. 4 shows that the lower mesospheric $\mathrm{O}_{3}$, and in particular the tertiary maximum that appears in winter, is captured with good confidence for each profile. The tertiary $\mathrm{O}_{3}$ maximum is observed from fall through spring in both years (2008 and 2009) with a magnitude between 1 ppmv and 3 ppmv, and is more pronounced in the fall than in spring.

The $\mathrm{O}_{3}$ concentrations during the summertime, which we define as the period when the solar elevation angle stays above $0^{\circ}$ throughout a $24 \mathrm{~h}$ period (13 November to 28 January), vary between 0 and $1 \mathrm{ppmv}$ near $60 \mathrm{~km}$, and between 0 and 0.3 ppmv near $72 \mathrm{~km}$.

\subsection{Error characterization}

The standard deviation $(1-\sigma)$ of the random measurement error of the $\mathrm{O}_{3}$ retrieval is estimated by propagating the measurement noise on the spectra through the inversion 


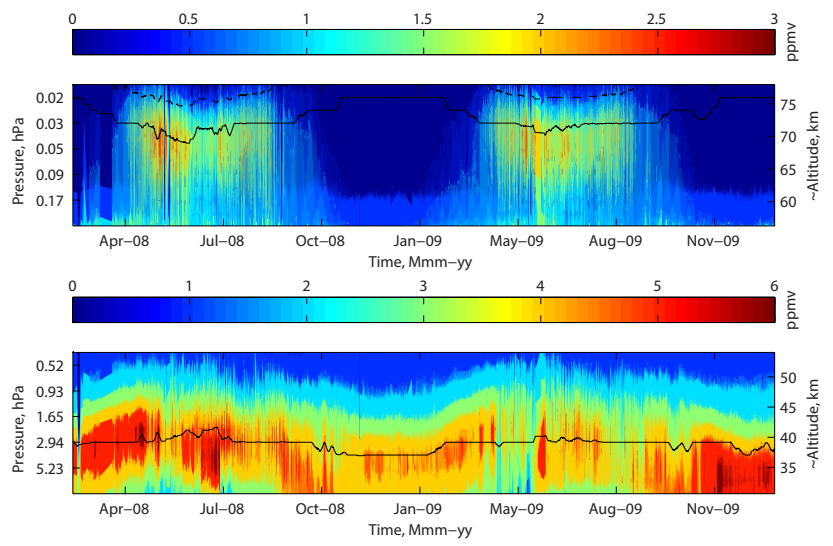

Figure 4. Top panel: BAS-MRT data showing the mesospheric ozone. The solid black line indicates the upper limit of the 0.8 measurement response, while the dashed black line indicates the upper limit of 0.5 measurement response. Bottom panel: stratospheric ozone observations from BAS-MRT. The solid black line indicates the lower limit of the 0.8 measurement response.

(Rodgers, 2004). The 1- $\sigma$ total systematic error is estimated by perturbing the atmospheric temperatures, the calibration, the line intensity and the air-broadening parameters with their respective uncertainties. The perturbations will propagate and affect the resulting profile trough the retrieval routine, and the errors are found from the difference to the original set-up. The atmospheric temperature is perturbed by $\pm 5 \mathrm{~K}$, which is the upper limit of the 1-sigma variability of the 20-year SD-WACCM temperature climatology above Troll. For the estimation of the calibration error we take into account the uncertainties in the hot/cold load calibration, standing waves, line of sight and tropospheric correction factor, and find that it is equivalent to, at most, a $10 \%$ variation of the tropospheric correction factor (Jarchow and Hartogh, 1994; De Wachter et al., 2011; Straub et al., 2013). Thus the total calibration error, including the uncertainty in the tropospheric correction, is taken to be $10 \%$ of the tropospheric correction factor. For the spectroscopic parameters we assume the line intensity has an uncertainty of $\pm 2 \%$, and for the air-broadening parameter we assume $\pm 5 \%$ (Rothman et al., 2009). The variability in the a priori is set to $50 \%$ in order to simulate large changes observed in the mesospheric ozone.

We use midnight profiles to characterize the errors of the retrieved $\mathrm{O}_{3}$ profiles. The estimated errors in vmr are also representative of the noon profiles. The error estimations are displayed in Fig. 5, and show that the random measurement error is within $6 \%$ of the $\mathrm{O}_{3} \mathrm{vmr}$ and the total systematic error is within $9 \%$ at altitudes with a measurement response of at least 0.8 . The air-broadening parameter dominates the total systematic error at all altitudes, and is the largest error up to about $0.08 \mathrm{hPa}$, peaking at altitudes where the change in brightness temperature with frequency of the $\mathrm{O}_{3}$ spectra

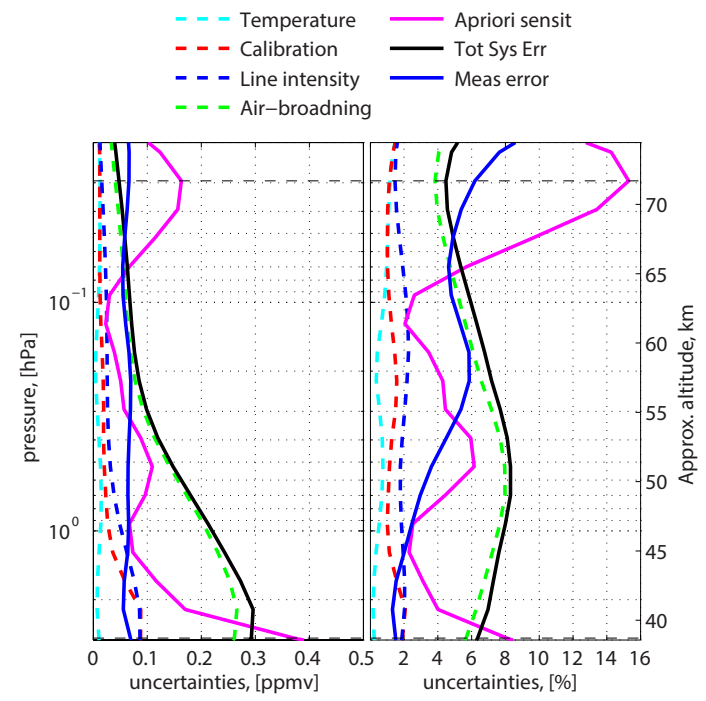

Figure 5. Error estimations of the BAS-MRT $\mathrm{O}_{3}$-retrieval: The black solid line shows the total systematic error, which is the rootsum-square of the dashed lines. The blue solid line is the random measurement error. The magenta solid line is the a priori sensitiviy. Dashed horizontal black lines indicate the upper/lower limit of the 0.8 measurement response. Left panel: uncertainties in ppmv representing all times. Right panel: uncertainties in $\%$ of midnight $\mathrm{O}_{3}$ profiles.

maximizes. The systematic errors given by the temperature, calibration and line-intensity are negligible at all altitudes. The estimation of the a priori sensitivity indicates where and how much the retrieved $\mathrm{O}_{3}$ profile is sensitive to the a priori. When the a priori is perturbed by $50 \%$, the resulting response is only larger than the systematic error below $2 \mathrm{hPa}(6-8 \%)$ and above $0.07 \mathrm{hPa}(6-15 \%)$.

\section{Comparison to Aura/MLS and SD-WACCM}

\subsection{Aura/MLS}

The Earth Observing System (EOS) Aura satellite was launched in July 2004 into a near polar, sun-synchronous orbit with a period of about $100 \mathrm{~min}$. The satellite crosses the equator on the ascending node at about 13:45 UTC \pm 15 min every day, repeating its ground track every 16 days. The Microwave Limb Sounder (MLS) aboard Aura provides day and night measurements of $\mathrm{O}_{3}$ from thermal emissions near $240 \mathrm{GHz}$. Validation of the version $2.2 \mathrm{O}_{3}$ data is given by Froidevaux et al. (2008) and reveals about 5-10\% difference in the ozone vmr in the stratosphere and 5-25\% in the mesosphere compared to other satellites. We use the version 3.3 $\mathrm{O}_{3}$ retrievals which are described by Livesey et al. (2011). The retrieved $\mathrm{O}_{3}$ profiles cover a pressure range between $215 \mathrm{hPa}$ and $0.02 \mathrm{hPa}$ with a vertical resolution of about $3 \mathrm{~km}$ in the stratosphere and about $5 \mathrm{~km}$ in the mesosphere. For the comparison we use profiles within $\pm 1^{\circ}$ latitude and 
$\pm 5^{\circ}$ longitude with respect to the Troll station $\left(72^{\circ} 01^{\prime} \mathrm{S}\right.$, $02^{\circ} 32^{\prime} \mathrm{E}$ ), resulting in 419 days with profiles available at about midnight and/or around 15 UTC.

\subsection{SD-WACCM}

The Whole Atmosphere Community Climate Model (WACCM) is a general circulation model coupled with the Community Atmospheric Model (CAM) chemistry model from the National Center for Atmospheric Research (NCAR). WACCM incorporates wave parameterization, molecular diffusion, and some space weather effects as described by Garcia et al. (2007). It is usually operated as a free-running climatological model, but the Specified Dynamics (SD-WACCM) version is relaxed toward meteorological fields (e.g. temperature, zonal and meridional winds, and surface pressure) from GEOS-5.2 in the troposphere and stratosphere up to approximately $40 \mathrm{~km}$, and then linearly relaxed toward the free-running model from 40 to $50 \mathrm{~km}$ (Marsh, 2011; Lamarque et al., 2012). The latitude and longitude resolution of SD-WACCM is $1.9^{\circ} \times 2.5^{\circ}$. Each profile is given at 88 pressure levels with approximately two grid points per scale height. The corresponding altitude range from the surface to about $150 \mathrm{~km}$. For the comparison we use SD-WACCM midnight profiles at the grid point nearest to Troll station.

\subsection{Results}

For the following comparisons we generate a set of timecoincident profiles between BAS-MRT and MLS, and BASMRT and SD-WACCM. The requirement is that the profiles should be within one hour of each other, resulting in a set of 582 profiles for MLS and 630 profiles for SD-WACCM. Since both MLS and SD-WACCM have a better altitude resolution than BAS-MRT, we convolve their profiles with the AVK from the BAS-MRT data inversion.

\subsection{Temporal variations}

To address the reliability of the temporal variations resolved by BAS-MRT we compare co-incident vmr values at three independent pressure levels $(2.21,0.39$ and $0.04 \mathrm{hPa})$ corresponding to the upper stratosphere, near the stratopause, and the middle mesosphere (which includes the tertiary maximum). The correlation between MLS and BAS-MRT and SD-WACCM and BAS-MRT is carried out between the datasets for the entire measurement period. However, due to the large winter to summer variations of the ozone concentrations, particularly in the mesosphere, the correlation analysis is also carried out for the winter and summer seasons separately. We only report correlation coefficients that are statistically significant at greater than the $95 \%$ confidence level. For convenience in the discussion of the correlation coefficients, we refer to correlations $\geq 0.7$ as strong, from 0.3 to 0.7 as moderate, and $<0.3$ as weak. We first discuss temporal variations on timescales larger than 20 days, and then variations on timescales shorter than 20 days.

The left panels in Fig. 6 show the temporal behavior for all available co-incident data points as well as for the low frequency variations (timescales $>20$ days) for the co-incident MLS and BAS-MRT data set at three independent pressure levels. In the stratosphere (lower panel), the agreement appear very good in 2008 however a bias seem to appear in 2009. In the middle mesosphere (top panel), the agreement appear overall very good, in particular the diurnal cycle of ozone is seen in spring and fall for the data points. The right panel in Fig. 6 shows the correlation coefficients between the low-pass filtered data of BAS-MRT and MLS. It can be seen that the overall correlation (red solid line) is strong at all altitudes. This correlation is largely dominated by the seasonal variations, particularly in the middle mesosphere (top left panel in Fig. 6). However, the seasonal effect is smaller in the stratosphere (bottom left panel in Fig. 6) and the correlation reflects intraseasonal dynamical variations. In winter, the strong correlation (red dashed line) is preserved at all altitudes indicating that dynamical and chemical changes on time-scales larger than 20 days are well captured by BASMRT. In summer, the correlation (red dotted line) is still strong in the stratosphere but weakens with increasing altitude as we enter the mesospheric minimum, even though BAS-MRT measures above its random noise-level. We believe this is due to the random noise in single MLS profiles (with an approximate integration time of $<90$ s) gradually becoming larger than the measured vmr values in this region (Fig. 9).

Figure 7 is the equivalent to Fig. 6, but the comparison is between BAS-MRT and SD-WACCM and for midnight values only. The left panels in Fig. 7 indicates that in general, the observations from BAS-MRT agrees well with the modeled vmr values from SD-WACCM. The right panel in Fig. 7 shows that the overall correlation (blue solid line) of the low frequency variations between SD-WACCM and BAS-MRT is generally strong. It weakens around the stratopause, which is where the minimum between the stratospheric ozone layer and the tertiary maximum occurs. Due to the strong concentration gradients in this region, small deviations in the maxima locations would lead to larger deviations and poorer correlation between the ozone variations. In winter, the correlation (blue dashed line) stays moderate at all pressure levels. The summer correlation coefficients (blue dotted line) are strong in the stratosphere but, they do not reveal a consistent picture at higher altitudes corresponding to where SDWACCM is no longer driven by GEOS-5.2 data. However, the general agreement in the comparison between BAS-MRT and both MLS and SD-WACCM indicates that the atmospheric variability on time-scales exceeding 20 days is well captured by BAS-MRT.

The left panels in Fig. 8 show the higher frequency vmr variations for SD-WACCM, MLS and BAS-MRT for the 

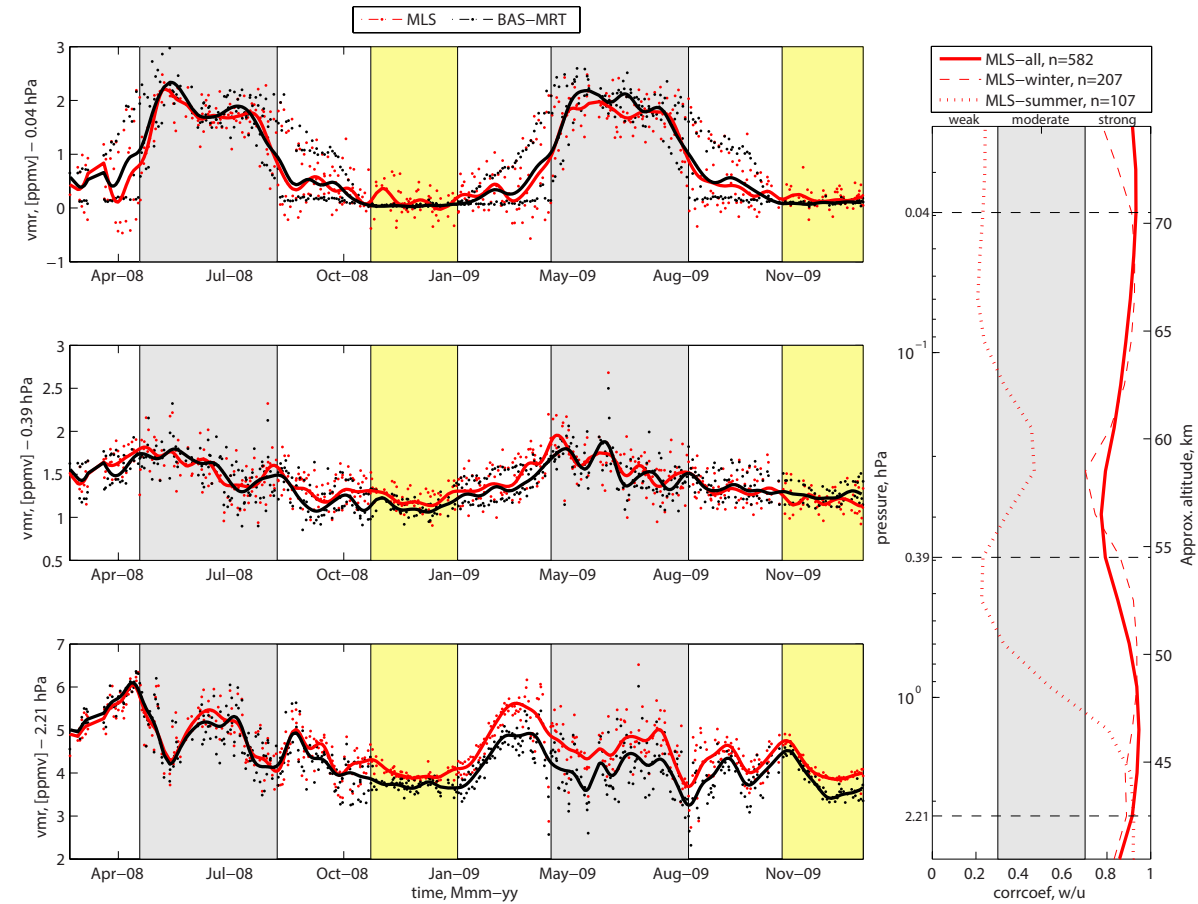

Figure 6. Time series of co-incident data between MLS and BAS-MRT at three independent pressure levels. Data are taken near 00 UTC and 15 UTC. Left panels: dots mark the individual data points for the datasets, and solid lines show the low-pass filtered data with a 20-day cut-off. Grey shading marks the winter season defined by solar elevation angles below $-30^{\circ}$, while yellow shading marks the summer defined by solar elevation angles above $0^{\circ}$. The areas without shading represent spring and fall, and in the mesosphere the diurnal signature can be seen in the data points. Right panel: calculated correlation coefficients for the low-pass filtered data between BAS-MRT and MLS. The thick solid line is for the entire measurement period, while dashed and dotted lines represent the correlation coefficients for the winter and summer respectively. The number of correlated data points $(n)$ is listed in the legend for the respective calculations.

same pressure levels as above (Figs. 6 and 7). The vmr variations are found by subtracting the low-pass filtered data from their respective datasets, which effectively creates a high-pass filter for time scales shorter than 20 days (Kennedy, 1980). The result indicates variations of similar magnitude for all the data sets in the stratosphere and around the stratopause, while in the mesosphere MLS observes larger variations than BAS-MRT and SD-WACCM, particularly during summer. The right panel in Fig. 8 shows the calculated correlation coefficients between the high-pass filtered data of BAS-MRT and both MLS and SD-WACCM. Discussing the result between MLS and BAS-MRT first, it can be seen that the overall short-term correlation is strong in both the stratosphere and mesosphere, indicating that atmospheric variations on time scales shorter than 20-days are well captured by BAS-MRT. Looking closer at the vmr variations in winter, the correlation stays strong in the stratosphere but becomes moderate in the mesosphere. The summer time vmr variations correlate moderately in the stratosphere, but since the vmr values in the summertime fall below the random noise level of MLS, the correlation becomes, as expected, insignificant. Despite SD-WACCM being poorly suited for characterizing short term variations in the ozone at a single location and time, the overall correlation with BAS-MRT is still moderate/strong at around $40 \mathrm{~km}$ where it is driven by the reanalysis data. As SD-WACCM is linearly relaxed to the free running mode by $50 \mathrm{~km}$, the correlation weakens and becomes insignificant in the middle mesosphere.

\subsection{Comparison of profiles}

The comparison between $\mathrm{O}_{3}$ profiles from BAS-MRT and Aura MLS, and those from BAS-MRT and SD-WACCM, are carried out following the procedures by Stiller et al. (2012). Below, the BAS-MRT profiles that are co-incident with MLS (00:00 UTC + 15:00 UTC) and SD-WACCM (midnight only) are highlighted with (m) and (w) respectively. Figure 9a shows the overall mean of the $\mathrm{O}_{3}$ profiles from BASMRT(m), MLS, BAS-MRT(w) and SD-WACCM. In general there is a very good agreement between the profiles. However, MLS shows slightly higher values at about $3 \mathrm{hPa}$ than BAS-MRT $(m)$ in both winter and summer (Fig. 9d and g), whereas SD-WACCM shows slightly lower values in winter at about $3 \mathrm{hPa}$ than BAS-MRT(w).

Figure $9 \mathrm{~b}$ displays the average difference (bias) and standard error of that difference between the profiles, together 

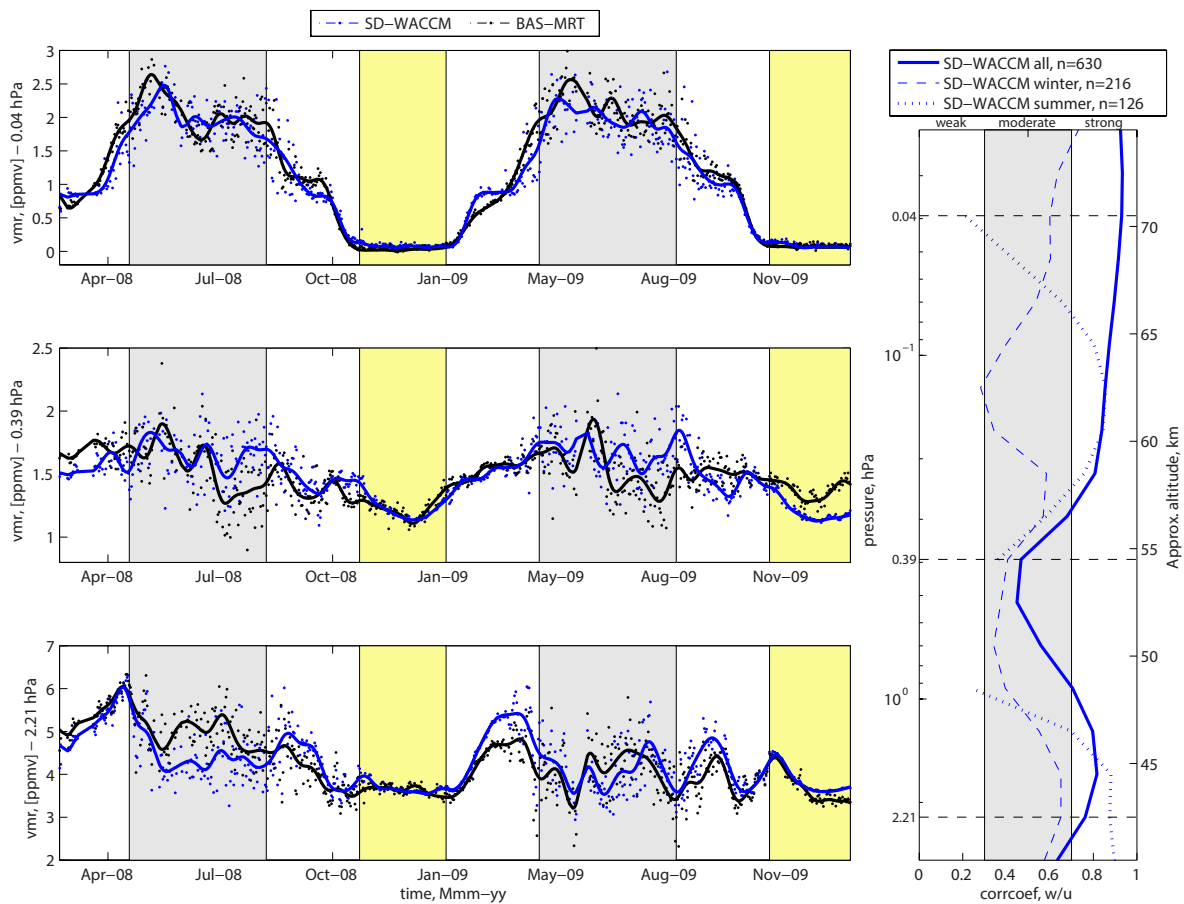

Figure 7. Same as Fig. 6, but for BAS-MRT and SD-WACCM. Data are from midnight only.
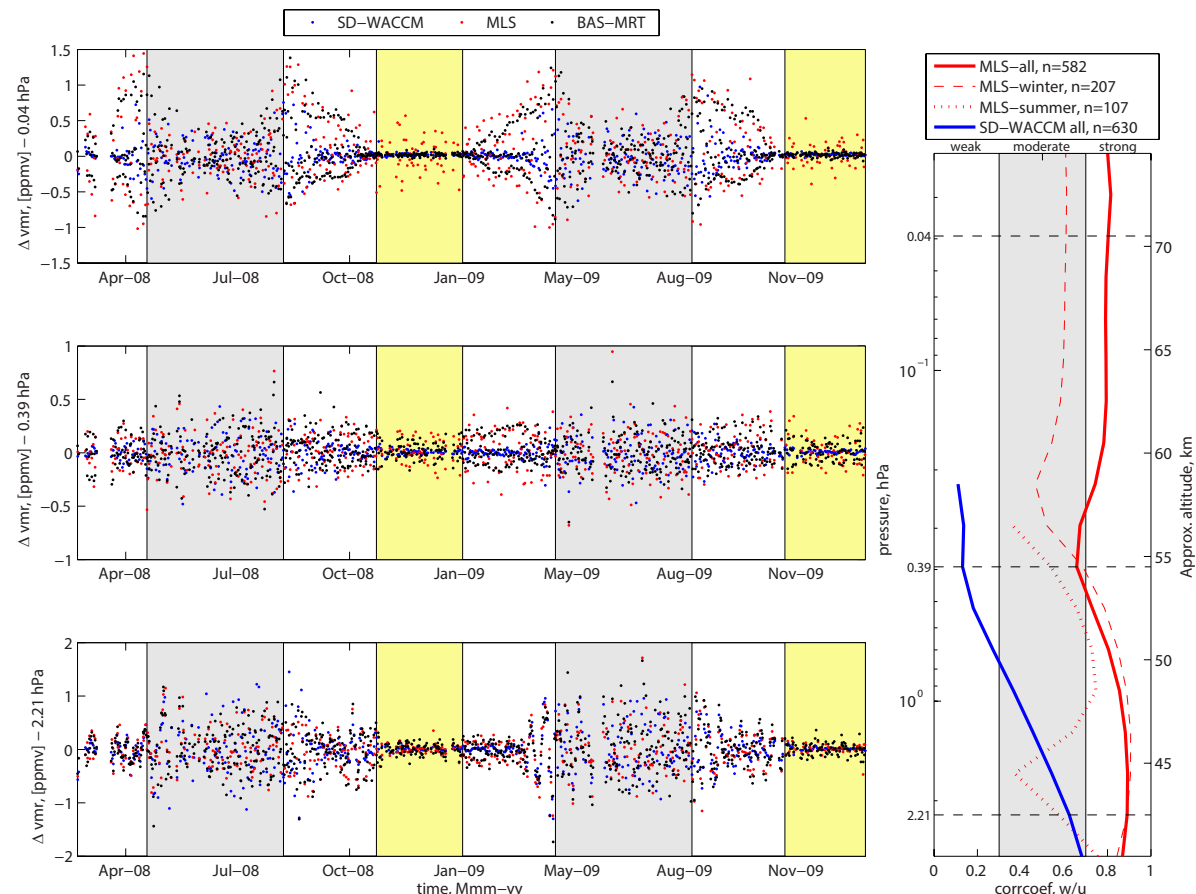

Figure 8. Same as Figs. 6 and 7, but for high-passed filter data with a 20-day cut-off (low-pass filter subtracted from the data). 

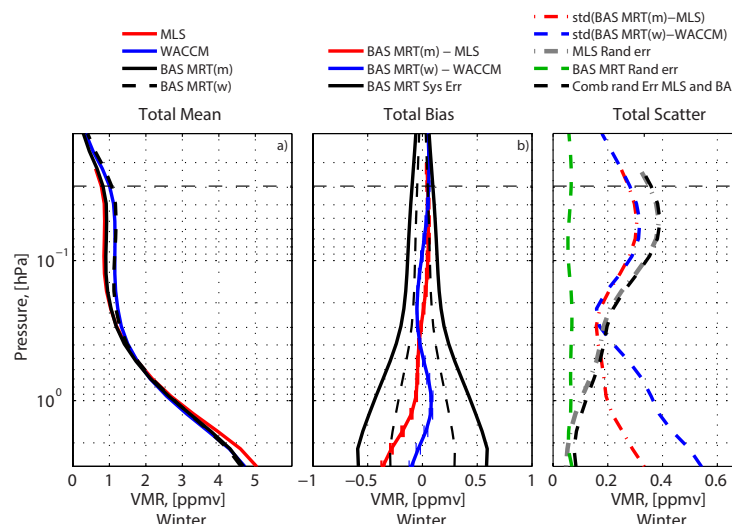

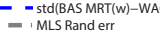
- BAS MRT Rand err

Total Bias

Total Scatter
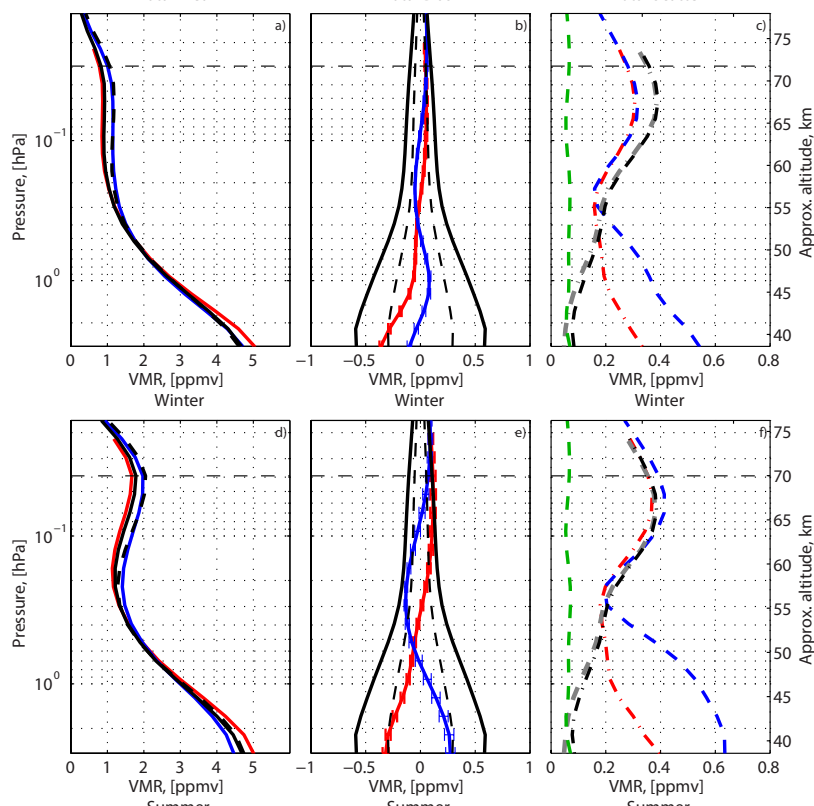

Summer
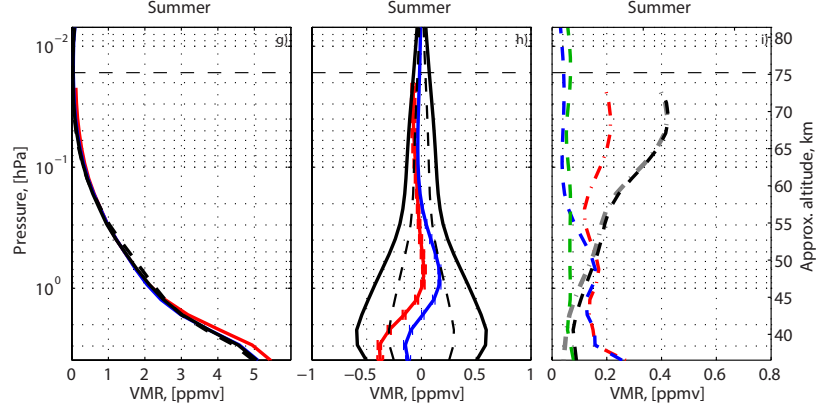

Figure 9. Intercomparison between BAS-MRT, MLS and SDWACCM using co-incident profiles; (m) labels MLS and (w) labels SD-WACCM: (a, b and c) overall comparison from available coincident data. (d, e and f) Comparison from summer time (yellow area in Figs. 6 and 7). (g, $\mathbf{h}$ and i) Comparison from winter time (grey area in Figs. 6 and 7). Left panels: mean of midnight profiles. Middle panels: the bias with the $1-\sigma$ of the standard error of the bias. The black solid (dashed) line is the $\pm 2-\sigma( \pm 1-\sigma)$ of the total systematic error of BAS-MRT. Right panels: standard deviation of the bias between the co-incident profiles of BAS-MRT to MLS and SD-WACCM. The combined and individual random errors of MLS and BAS-MRT for midnight values are also shown.

with the estimated systematic error of BAS-MRT. The total biases between the instruments and model are within the 2- $\sigma$ systematic error estimate of BAS-MRT at all altitudes, and within 1- $\sigma$ at most altitudes. While the altitude behavior of the bias varies from winter to summer, particularly between BAS-MRT(w) and SD-WACCM, these variations are sill within the 2- $\sigma$ systematic error of the instrument and at most altitudes within the $1-\sigma$. Thus, there is no signifi- cant bias between BAS-MRT(m) and MLS, or between BASMRT(w) and SD-WACCM.

Figure $9 \mathrm{c}, \mathrm{f}$ and i display the standard deviation of the difference between the profiles, together with the individual and combined random errors of BAS-MRT and MLS, for overall, winter and summer respectively. If the instrument observations are truly co-incident in space and time, we expect the standard deviation between the observations to fall within the combined random error estimates of the instruments. In the mesosphere the combined random error estimates of the BAS-MRT and MLS instruments are large and accounts for the standard deviation of the difference between their observations. In the stratosphere, where the MLS measurement precision becomes better, there is more sensitivity to the spatial and temporal differences between the measurements. This is reflected by the standard deviation between the two observations becoming greater than their combined estimated random errors, particularly in winter when small-scale wave activity is higher (Alexander et al., 2011).

Apart from the summer mesosphere, when $\mathrm{O}_{3}$ levels are very low, the random deviations between BAS-MRT and SDWACCM are larger than the estimated instrumental random error at all altitudes. This is likely because SD-WACCM does not resolve the short period or short wavelength variations that will affect the observations. Similar to the MLS comparisons in the stratosphere, the larger deviations in the winter than in the summer, point to gravity waves as the source of these variations (Alexander et al., 2011). However, it may also be that the estimated random error of BAS-MRT is underestimated.

\section{Conclusions}

This paper describes and presents the $\mathrm{O}_{3}$ measurements from the British Antarctic Survey's microwave radiometer stationed at Troll, Antarctica from February 2008 through January 2010 . The retrieval of the hourly $\mathrm{O}_{3} \mathrm{vmr}$ values resulted in 13648 profiles over 675 days (of 715 possible days) with an average of about 20 profiles per day. The retrieved profiles cover the pressure range from $3 \mathrm{hPa}$ to $0.02 \mathrm{hPa}$ (approximately $38-72 \mathrm{~km}$ ) which includes the topside of the stratospheric ozone layer and the bottom side of the tertiary maximum in the mesosphere. Comparison of BAS-MRT to Aura/MLS and SD-WACCM shows a good correlation indicating that the atmospheric variability on time-scales both larger and shorter than 20 days is well captured by BASMRT. Taken seasonally, a weaker correlation is found for both the long-term and short-term variations in summer when most of the vmr values are below the random noise level in Aura/MLS. At all altitudes the comparison of $\mathrm{O}_{3}$ profiles between BAS-MRT and MLS and SD-WACCM reveals no significant bias in the measured vmr values outside the systematic errors of the instrument. 
The results presented in this paper indicate that the retrieved $\mathrm{O}_{3}$ profiles from BAS-MRT are well suited for studies of the upper stratospheric and middle mesospheric ozone, including the tertiary maximum. The data quality will allow short ( hours), seasonal and inter-seasonal $\mathrm{O}_{3}$ variations to be observed, including effects from transient events such as particle precipitation. The dataset presented here are available for public use and can be downloaded from the UK's Polar Data Center at http://doi.org/nc3. The instrument is continuing polar observations from Halley $\left(75^{\circ} 35^{\prime} \mathrm{S}, 26^{\circ} 39^{\prime} \mathrm{W}\right)$, Antarctica from the Austral autumn 2013 season onwards, measuring middle atmospheric $\mathrm{CO}, \mathrm{NO}$ and $\mathrm{O}_{3}$ while viewing toward the South Pole.

Acknowledgements. We gratefully thank Ole Martin Christensen for help on the implementation and understanding of ARTS 2. Stephan Thomas Kral has contributed with valuable discussions on interpretation of the intercomparison. We thank Mark Clilverd at BAS, Kim Holmén at the Norwegian Polar Institute (NPI) and Paul Hartogh at the Max Planck Institute (MPI, Germany) for their support of the BAS microwave radiometer. We also thank the Troll station over-wintering engineers Atle Markussen, Asbjørn Djupdal, and Tore Dahl as well as David Maxfield and Paul Breen at BAS for their help. Corinne Straub was funded by the Norwegian Polar Institute Antarctic Program under the grant Observations of carbon monoxide and ozone in the Antarctic and Arctic: Implications for the Inter-hemispheric coupling of vertical motions. The BAS microwave radiometer project is funded by the Natural Environment Research Council (UK).

Edited by: D. Carlson

\section{References}

Alexander, S. P., Klekociuk, A. R., and Murphy, D. J.: Rayleigh lidar observations of gravity wave activity in the winter upper stratosphere and lower mesosphere above Davis, Antarctica $\left(69^{\circ} \mathrm{S}, 78^{\circ} \mathrm{E}\right)$, J. Geophys. Res., 116, D13109, doi:10.1029/2010JD015164, 2011.

Baron, P., Ricaud, P., de la Noë, J., Eriksson, J., Merino, F., Ridal, M., and Murtagh, D.: Studies for the Odin sub-milimetre radiometer. II. Retrieval methodology, Can. J. Phys., 80, 341-356, doi:10.1139/P01-150, 2002.

Christensen, O. M. and Eriksson, P.: Time series inversion of spectra from ground-based radiometers, Atmos. Meas. Tech., 6, 15971609, doi:10.5194/amt-6-1597-2013, 2013.

Daae, M., Espy, P., Nesse Tyssøy, H., Newnham, D., Stadsnes, J., and Søraas, F.: The effect of energetic electron precipitation on middle mesospheric night-time ozone during and after a moderate geomagnetic storm, Geophys. Res. Lett., 39, L21811, doi:10.1029/2012GL053787, 2012.

De Wachter, E., Haefele, A., and Kämpfer, N.: The Seoul Water Vapor Radiometer for the Middle Atmosphere: Calibration, Retrieval, and Validation, Geoscience and Remote Sensing, IEEE Transactions on, 49, 1052-1062, doi:10.1109/TGRS.2010.2072932, 2011.
Demissie, T. D., Kleinknecht, N. H., Hibbins, R. E., Espy, P. J., and Straub, C.: Quasi-16 day period oscillations observed in middle atmospheric ozone and temperature in Antarctica, Ann. Geophys., 31, 1279-1284, doi:10.5194/angeo-31-1279-2013, 2013.

Dicke, R. H. and Beringer, R.: Microwave radiation from the sun and moon, Astrophys. J., 103, 375-276, 1946.

Eriksson, P., Jiménez, C., and Buehler, S. A.: Qpack, a general tool for instrument simulation and retrieval work, J. Quant. Spectrosc. Radia. Transfer, 91, 47-64, doi:10.1016/j.jqsrt.2004.05.050, 2005.

Eriksson, P., Buehler, S., Davis, C., Emde, C., and Lemke, O.: ARTS, the atmospheric radiative transfer simulator, version 2, J. Quant. Spectrosc. Radia. Transfer, 112, 1551-1558, doi:10.1016/j.jqsrt.2011.03.001, 2011.

Espy, P., Hartogh, P., and Holmén, K.: A microwave radiometer for the remote sensing of nitric oxide and ozone in the middle atmosphere, in: Remote Sensing of Clouds and the Atmosphere XI, Proc. SPIE, vol. 6362, doi:10.1117/12.688953, 2006.

Forkman, P., Christensen, O. M., Eriksson, P., Urban, J., and Funke, B.: Six years of mesospheric $\mathrm{CO}$ estimated from ground-based frequency-switched microwave radiometry at $57^{\circ} \mathrm{N}$ compared with satellite instruments, Atmos. Meas. Tech., 5, 2827-2841, doi:10.5194/amt-5-2827-2012, 2012.

Froidevaux, L., Jiang, Y. B., Lambert, A., Livesey, N. J., Read, W. G., Waters, J. W., Browell, E. V., Hair, J. W., Avery, M. A., McGee, T. J., Twigg, L. W., Sumnicht, G. K., Jucks, K. W., Margitan, J. J., Sen, B., Stachnik, R. A., Toon, G. C., Bernath, P. F., Boone, C. D., Walker, K. A., Filipiak, M. J., Harwood, R. S., Fuller, R. A., Manney, G. L., Schwartz, M. J., Daffer, W. H., Drouin, B. J., Cofield, R. E., Cuddy, D. T., Jarnot, R. F., Knosp, B. W., Perun, V. S., Snyder, W. V., Stek, P. C., Thurstans, R. P., and Wagner, P. A.: Validation of Aura Microwave Limb Sounder stratospheric ozone measurements, J. Geophys. Res., 113, D15S20, doi:10.1029/2007JD008771, 2008.

Garcia, R. R., Marsh, D. R., Kinnison, D. E., Boville, B. A. and Sassi, F.: Simulation of secular trends in the middle atmosphere, 1950-2003, J. Geophys. Res., 112, D09301, doi:10.1029/2006JD007485, 2007.

Hartogh, P. and Hartmann, G. K.: A high-resolution chirp transform spectrometer for microwave measurements, Meas. Sci. Technol., 1, 592-595, doi:10.1088/0957-0233/1/7/008, 1990.

Hartogh, P., Jarchow, C., Sonnemann, G. R., and Grygalashvyly, M.: On the spatiotemporal behavior of ozone within the upper mesosphere/mesopause region under nearly polar night conditions, J. Geophys. Res., 109, D18303, doi:10.1029/2004JD004576, 2004.

Hays, P. B. and Roble, R. G.: Observation of mesospheric ozone at low latitudes, Planet. Space Sci., 21, 273-279, 1973.

Jackman, C. H., Marsh, D. R., Vitt, F. M., Garcia, R. R., Randall, C. E., Fleming, E. L., and Frith, S. M.: Long-term middle atmospheric influence of very large solar proton events, J. Geophys Res., 114, D11304, doi:10.1029/2008JD011415, 2009.

Jarchow, C. and Hartogh, P.: Retrieval of Mesospheric Ozone from Groundbased millimeter wave Observations, Geoscience and Remote Sensing Symposium, 3, 1700-1703, doi:10.1109/IGARSS.1994.399542, 1994

Kennedy, J. S.: Comments on: On detrending and smoothing random data by A. J. Owens, J. Geophys. Res., 85, 219-220, doi:10.1029/JA085iA01p00219, 1980. 
Lamarque, J.-F., Emmons, L. K., Hess, P. G., Kinnison, D. E., Tilmes, S., Vitt, F., Heald, C. L., Holland, E. A., Lauritzen, P. H., Neu, J., Orlando, J. J., Rasch, P. J., and Tyndall, G. K.: CAM-chem: description and evaluation of interactive atmospheric chemistry in the Community Earth System Model, Geosci. Model Dev., 5, 369-411, doi:10.5194/gmd-5-369-2012, 2012.

Livesey, N. J., Read, W. G., Froidevaux, L., Lambert, A., Manney, G. L., Pumphrey, H. C., Santee, M. L., Schwartz, M. J., Wang, S., Cofield, R. E., Cuddy, D. T., Fuller, R. A., Jarnot, R. F., Jiang, J. H., Knosp, B. W., Stek, P. C., Wagner, P. A., and Wu, D. L.: EOS/MLS Version 3.3. Level 2 data quality and description document, Tech. Rep. Jet Propulsion Laboratory, pp. D-33509, 2011.

Marsh, D.: Chemical-dynamical coupling in the mesosphere and lower thermosphere, Aeronomy of the Earth's Atmosphere and Ionosphere, IAGA Special Sopron Book Series, 2, 3-17, doi:10.1007/978-94-007-0326-1, 2011.

Marsh, D., Smith, A., Brasseur, G., Kaufmann, M., and Grossmann, K.: The existence of a tertiary ozone maximum in the highlatitude middle mesosphere, Geophys. Res. Lett., 28, 4531-4534, 2001

McDermid, I. S., Bergwerff, J. B., Bodeker, G., Boyd, I. S., Brinksma, E. J., Connor, B. J., Farmer, R., Gross, M. R., Kimvilakani, P., Matthews, W. A., McGee, T. J., Ormel, F. T., Parrish, A., Singh, U., Swart, D. P. J., and Tsou, J. J.: OPAL: Network for the Detection of Stratospheric Change ozone profiler assessment at Lauder, New Zealand 1. Blind intercomparison, J. Geophys. Res., 103, 28683-28692, doi:10.1029/98JD02706, 1998.

Muscari, G., Cesaroni, C., Fiorucci, I., Smith, A. K., Froidevaux, L., and Mlynzak, M.: Strato-mesospheric ozone measurements using ground-based millimeter-wave spectroscopy at Thule, Greenland, J. Geophys. Res., 117, D07307, doi:10.1029/2011JD016863, 2012.

Nemuc, A. and De Zafra, R. L.: Ozone profiles over the South Pole from ground-based retrievals and satellite data, J. Optoelectron. Adv. Mater., 9, 3533-3540, 2007.

Newnham, D. A., Espy, P. J., Clilverd, M. A., Rodger, C. J., Seppälä, A., Maxfield, D. J., Hartogh, P., Holmén, K., and Horne, R. B.: Direct observations of nitric oxide produced by energetic electron precipitation into the Antarctic middle atmosphere, Geophys. Res. Lett., 38, L20104, doi:10.1029/2011GL048666., 2011.

Orte, P. F., Salvador, J., Wolfram, E., D’Elia, R., Nagahama, T., Kojima, Y., Tanada, R., Kuwahara, T., Morihira, A., Quel, E., and Mizuno, A.: Millimeter wave radiometer installation in Rio Gallegos, southern Argentina, in: Int. Conf. on Applications of Opt. and Photonics, edited by Costa, MFM, vol. 8001 of Proceedings of SPIE, doi:10.1117/12.894578, 2011.

Palm, M., Hoffmann, C. G., Golchert, S. H. W., and Notholt, J.: The ground-based MW radiometer OZORAM on Spitsbergen - description and status of stratospheric and mesospheric O3-measurements, Atmos. Meas. Tech., 3, 1533-1545, doi:10.5194/amt-3-1533-2010, 2010.

Parrish, A.: Millimeter-wave remote sensing of ozone and trace constituents in the stratosphere, Proc. IEEE, 82, 1915-1929, 1994.

Randall, C. E., Harvey, V. L., Singleton, C. S., Bernath, P. F., Boone, C. D., and Kozyra, J. U.: Enhanced $\mathrm{NO}_{\mathrm{x}}$ in 2006 linked to strong upper stratospheric Arctic vortex, Geophys. Res. Lett., 33, D08308, doi:10.1029/2006GL027160, 2006.

Rodgers, C. D.: Inverse methods for atmospheric sounding: Theory and Practice, vol. 2 of Series on Atmospheric, Ocean and Planetary Physics, World Scientific, 2004.

Rothman, L., Gordon, I., Barbe, A., Benner, D., Bernath, P., Birk, M., Boudon, V., Brown, L., Campargue, A., Champion, J.-P., Chance, K., Coudert, L., Dana, V., Devi, V., Fally, S., Flaud, J.M., Gamache, R., Goldman, A., Jacquemart, D., Kleiner, I., Lacome, N., Lafferty, W., Mandin, J.-Y., Massie, S., Mikhailenko, S., Miller, C., Moazzen-Ahmadi, N., Naumenko, O., Nikitin, A., Orphal, J., Perevalov, V., Perrin, A., Predoi-Cross, A., Rinsland, C., Rotger, M., Simeckova, M., Smith, M., Sung, K., Tashkun, S., Tennyson, J., Toth, R., Vandaele, A., and Auwera, J. V.: The HITRAN 2008 molecular spectroscopic database, J. Quant. Spectrosc. Radia. Transfer, 110, 533-572, doi:10.1016/j.jqsrt.2009.02.013, 2009.

Solomon, S., Crutzen, P. J., and Roble, R. G.: Photochemical Coupling Between the Thermosphere and the Lower Atmosphere 1. Odd Nitrogen From 50 to 120 km, J. Geophys. Res., 87, 72067220, 1982.

Sonnemann, G., Hartogh, P., Jarchow, C., Grygalashvyly, M., and Berger, U.: On the winter anomaly of the night-today ratio of ozone in the middle to upper mesosphere in middle to high latitudes, Adv. Space Res., 40, 846-854, doi:10.1016/j.asr.2007.01.039, 2007.

Stiller, G. P., Kiefer, M., Eckert, E., von Clarmann, T., Kellmann, S., García-Comas, M., Funke, B., Leblanc, T., Fetzer, E., Froidevaux, L., Gomez, M., Hall, E., Hurst, D., Jordan, A., Kämpfer, N., Lambert, A., McDermid, I. S., McGee, T., Miloshevich, L., Nedoluha, G., Read, W., Schneider, M., Schwartz, M., Straub, C., Toon, G., Twigg, L. W., Walker, K., and Whiteman, D. N.: Validation of MIPAS IMK/IAA temperature, water vapor, and ozone profiles with MOHAVE-2009 campaign measurements, Atmos. Meas. Tech., 5, 289-320, doi:10.5194/amt-5-289-2012, 2012.

Straub, C., Espy, P. J., Hibbins, R. E., and Newnham, D. A.: Mesospheric CO above Troll station, Antarctica observed by a ground based microwave radiometer, Earth Syst. Sci. Data, 5, 199-208, doi:10.5194/essd-5-199-2013, 2013.

Turunen, E., Verronen, P. T., Seppälä, A., Rodger, C. J., Clilverd, M. A., Tamminen, J., Enell, C.-F., and Ulich, T.: Impact of different energies of precipitating particles on $\mathrm{NO}_{\mathrm{x}}$ generation in the middle and upper atmosphere during geomagnetic storms, J. Atmos. Solar-Terr. Phys., 71, 1176-1189, 2009.

Verronen, P. T., Rodger, C. J., Clilverd, M. A., and Wang, S.: First evidence of mesospheric hydroxyl response to electron precipitation from the radiation belts, J. Geophys. Res., 116, D07307, doi:10.1029/2010JD014965, 2011.

Villanueva, G. L. and Hartogh, P.: The high resolution chirp transform spectrometer for the SOFIA-GREAT instruments, Experimental Astronomy, 18, 77-91, doi:10.1007/s10686-005-9004-3, 2004.

Villanueva, G. L., Hartogh, P., and Reindl, L.: A digital dispersive matching network for SAW devices in chirp transform spectrometers, IEEE Trans. Microw. Theory Tech., 54, 1415-1424, doi:10.1109/TMTT.2006.871244, 2006. 